\title{
In-silico Analysis of Porcine and Recombinant Insulin Activity on Glycogen ${ }^{\dagger}$
}

\author{
Ezra Leander Santhosh ${ }^{1, *}$, Navinraj Theneri Irudhayaraj ${ }^{2}$, Kishor Elango ${ }^{1}$, Julie Selvi Irudhayaraj ${ }^{3}$ \\ St.Joseph's College of Engineering, Chennai \\ Pasteur Institute of India, Coonoor \\ Christian Medical College and Hospital, Vellore \\ * Correspondence: leandersanthosh@gmail.com; \\ $\dagger$ Presented at International e-Conference on Bioengineering for Health and Environment (ICBHE 2020)
}

Received: 5.07.2020; Revised: 10.07.2020; Accepted: 12.07.2020; Published: 15.07.2020

\begin{abstract}
The study focuses on the anti-diabetic activity by molecular simulation of Recombinant Insulin, Porcine Insulin, and Glycogen. The sequence of these three molecules was retrieved, and 3D structures were modeled. A total of two different molecular simulations were carried out. The simulations were done using Autodock software. Initially, the downloaded PDB structures were docked with glycogen and the second between the active site peptide models of both insulin molecules based on castP prediction with glycogen molecule. The results were analyzed by the Ramachandran plot for model prediction, and the binding energy was set as criteria to determine the best-docked model. The binding energy of recombinant insulin, porcine insulin with glycogen was 0.32 and -1.09 , respectively. Similarly, the binding energy for peptide models with a glycogen molecule was found to be +1.09 and +6.76 , respectively. Based on the results, it was concluded that recombinant insulin has a higher affinity than porcine insulin.
\end{abstract}

Keywords: Recombinant Insulin; Porcine Insulin; Glycogen; Molecular simulations; Active site prediction.

(C) 2020 by the authors. This article is an open-access article distributed under the terms and conditions of the Creative Commons Attribution (CC BY) license (https://creativecommons.org/licenses/by/4.0/).

\section{Funding}

This research received no external funding.

\section{Acknowledgments}

This research has no acknowledgment.

\section{Conflicts of Interest}

The authors declare no conflict of interest. 